\title{
Neurologic Complications of Extracorporeal Membrane Oxygenation
}

\author{
Cristian Eduardo Navarro ${ }^{1 *}$, Aranza Helena Tafur Borrero ${ }^{2}$ and José Rosales Manjarrez ${ }^{1}$ \\ ${ }^{1}$ Clinical Neurology Unit, Medical Department, Medical School, Universidad Nacional de Colombia \\ ${ }^{2}$ Medical School, Universidad Nacional de Colombia
}

*Corresponding author: Cristian Eduardo Navarro, Clinical Neurology Unit, Medical Department, Medical School, Universidad

Nacional de Colombia

\section{ARTICLE INFO}

Received: 幽 June 11, 2019

Published: 慧 June 18, 2019

Citation: Cristian E Navarro, Aranza Helena Tafur B, José Rosales M. Neurologic Complications of Extracorporeal Membrane Oxygenation. Biomed J Sci \& Tech Res 18(5)-2019. BJSTR. MS.ID.003225.

Keywords: Brain Disease; Delirium; Extracorporeal Membrane Oxygenation; Seizure; Stroke $(\mathrm{MeSH})$

\begin{abstract}
Extracorporeal membrane oxygenation is a vital rescue technique for life support in patients with cardio-respiratory failure, which is associated with multiple neurologic complication in almost all patients; these syndromes had been classified as type 1 and 2 taking into account their clinical signs. The physician must have a high degree of intuition to diagnose them as soon as possible because there is a lot of confusion and the best resources for diagnosis are not always available. The treatment depends of each etiology to intervene, but the most important factor is the prevention of each neurologic event; the prognosis is variable, and many patients will have a mild sequela. This document summarizes the topic briefly and approaches it from multiple aspects.
\end{abstract}

Abbreviations: ECMO: Extracorporeal Membrane Oxygenation; V-V: Veno-Venous Configuration; V-A: Veno-Arterial Configuration; PLD's: Periodic Lateralized Discharges

\section{Introduction}

Extracorporeal membrane oxygenation (ECMO) is a vital rescue technique in patients with cardio-respiratory failure, which as an invasive procedure is not exempt from complications such as embolism, ischemia, coagulopathy, bleeding, hemolysis and infections, some of which can affect the central nervous system up to $50 \%$ of cases [1,2]; even interventions associated with therapy could affect the system, such as prolonged use of sedatives and analgesics that would lead to a withdrawal syndrome during or after ECMO withdrawal. These types of neurological complications described in this group of patients will then be reviewed, ranging from pathophysiology through diagnostic recommendations to exploring available prognostic information.

\section{Types of Neurologic Complications and their Etiology}

The neurological complications are diverse and have been classified into two large groups: acute instauration with focal sequelae such as stroke (type 1) and subacute instauration with generalized sequelae such as delirium and neurocognitive disorder (type 2). There are other types of alterations associated with those mentioned above such as seizures, hypoxic-ischemic encephalopathy, brain death and, to a lesser extent paraplegia by spinal cord infarction (few cases described) [3,4]. The Extracorporeal Life Support Organization (ELSO) registry that accounts with 4500 patients, reported an incidence of neurological complications of $20 \%$ between 2002-2004 and 13\% between 20112013 [5]; whereas the systematic review by Sutter et al reported an average of $13 \%$ and after excluding brain death and hypoxicischemic encephalopathy, stroke corresponded to 9\% [6]. There are no major differences in incidence with respect to veno-arterial (VA) versus veno-venous ( $\mathrm{V}-\mathrm{V})$ configuration. The best characterized etiology is embolization (gaseous, clots or atheromatous plaques), especially if the circuit is V-A. In ECMO V-V, it can also be given if there is right-to-left interatrial shunt. It has been reported that embolization may occur in varying degrees up to $100 \%$ of patients and its severity depends on the size of the thrombus and the affected artery; in this order of ideas, in this regard, it has been described that the V-A configuration has a $58 \%$ higher risk of neurological complications than the $\mathrm{V}-\mathrm{V}[1]$. 
Bleeding has been associated with the use of anticoagulants, decrease of fibrinogen and platelet count, and the mechanical destruction of cells that leads to endothelial activation and release of inflammatory cytokines, which in turn permeate the blood-brain barrier. Another etiology involved in cognitive impairment and watershed strokes is the global brain hypoperfusion secondary to mean arterial pressure lower than $30 \%$ of the basal, which causes a drop in cerebral perfusion pressure [7]; this also can occur in the ECMO V-A configuration with femoral artery cannulation, where a retrograde flow of oxygenated blood to the aortic arch and the carotids arteries is needed, if this phenomenon is compromised, there will be hypoxic-ischaemic encephalopathy. Other potential causality theories suggest the role of low hemoglobin during therapy, blood glucose $>200 \mathrm{mg} / \mathrm{dl}$, metabolic acidemia, hydroelectrolytic disorders, fever, female gender, renal replacement therapy, prolonged invasive mechanical ventilation, use of vasodilator sedatives and rapid drop in blood pressure and/ or carbon dioxide affecting cerebral self-regulation $[3,6]$. Regarding the V-A cannulation, Guennec et al found in their cohort that perform central cannulation of the cardiac cavities through open chest surgery is a risk factors for stroke with OR 3.2 (95\%CI 1.5-6.6 and $\mathrm{p}=0.002$ ) [8].

\section{Diagnostic Challenge}

The diagnosis is based on clinical suspicion by evaluating the patient under sedation and documenting anisocoria or unilateral changes of tone and reflexes; once sedation is removed, it could be determined any alteration of consciousness, additionally patients may have new onset-seizures or remain in a coma. It is recommended the use of computerized tomography which has a good performance to diagnose intracranial hemorrhage, concerning to brain ischemia must take into account the evolution time to correlate it with changes in relative density generated by cytotoxic edema. Neuropsychological tests contribute to determine the severity of cognitive impairment and their performance increases if the patient is previously studied as a baseline, which is uncommon because ECMO therapy is an emergency intervention. Another monitoring method is the use of infrared spectroscopy (NIRS) which evaluates the oxygenation of the cerebral parenchyma and is useful in V-A cannulation because of the possibility of irrigating the parenchyma with deoxygenated blood [9]. Transcranial doppler is not very useful since most emboli can be gaseous and not be visible in the study [10]. Electroencephalographic monitoring which is indicated in all patients under sedation in an intensive care unit, allows observing interictal and ictal activity corresponding to a non-convulsive crisis, as well as showing new onset-slow focal or generalized activity related to stroke or encephalopathy respectively. Epileptic seizures have been reported in up to $10 \%$ of patients $[6,11]$ and have been associated with the presence of PLD's (periodic lateralized discharges) secondary to structural injury.

The detection of neurologic complications is a challenge for the physician due to the patient's condition who is in a state of deep sedation, the unavailability of electroencephalographic monitoring and the impossibility to get a magnetic resonance imaging of patient's brain (sensitive study for ischemia) by his critical state and the non-magneto compatibility of the machines (ventilator, infusion pump or monitor). Based on these reasons, one study attempted to evaluated the usefulness of the $\mathrm{S} 100 \mathrm{~B}$ protein in serum as a neurological injury marker by comparing two small groups of patients with and wihtout ECMO therapy; it documented that almost all patients with or without therapy and with neurological injury or without it, can increase the protein, but by the fifth day the neurological injured patients have a higher serum concentration compared to the others patients $(0.426 \mu \mathrm{g} / \mathrm{l}$ [95\%CI $0.421 \mu \mathrm{g} / \mathrm{l}$ $0.652 \mu \mathrm{g} / \mathrm{l}]$ vs $0.102 \mu \mathrm{g} / \mathrm{l}$ [95\%CI $0.085 \mu \mathrm{g} / \mathrm{l}-0.135 \mu \mathrm{g} / \mathrm{l}] \mathrm{p}=0.011$ ) [2]. In addition, glial fibrillary acidic protein and specific neuronal enolase had been proposed as early biomarkers, because they are significantly elevated in patients with brain injury, however these proteins are also detected above the normal range in the control groups $[12,13]$.

\section{Treatment and Prognosis}

There are no different treatment options from those already known and the use of estrogens, magnesium sulfate, lidocaine, piracetam and glucocorticoids has been useless [7]. The main objective should be prevention, but it becomes a challenge because the patient's conditions generates an unpredictable outcome to interventions; for example, the use of heparin to prevent clot formation in the ECMO system facilitates bleeding, or the decrease flow to prevent "system cavitation" would favor cerebral hypoperfusion. Regarding the use of heparin or other ECMOassociated coagulopathy, the study by Luyt et al did not show a relationship between these factors and the incidence of intracranial hemorrhage after doing a univariate and multivariate analysis of the cohort of patients between 2006 and 2012 [14]. It is recommended to avoid cannulation of atheromatous arteries, cannulate an axillary artery or more central artery if hypoxia is detected with the femoral configuration, limit the reduction of arterial partial pressure of carbon dioxide, and use the lowest possible dose of heparin.

Prognosis is variable, more than $40 \%$ of affected patients reporting no clinical findings and another similar percentage reports evidence of abnormality in neuropsychological tests [7]; mortality is also variable depending on the cohort or caseseries assessed [15], but Sutter et al reported a median of $83 \%$ (interquartile range 54-100\%) compared to the group in ECMO without neurologic complications (median $42 \%$ and interquartile range $24-55 \%, p<0.001$ ] [6]; additionally they reported a median mortality rate of $96 \%$ for intracranial hemorrhage, $84 \%$ for cerebral infarction and $40 \%$ for epileptic seizures. In regard to the cognitive prognosis, Von Bahr et al in Sweden performed neuropsychological tests on survivors after 3-17 years of therapy, they found that the group with hypoxaemia during ECMO therapy had no lower cognitive performance in comparison with those who were not hypoxaemic, and likewise, there was no difference between veno- 
venous and veno-arterial configuration [16]; in contrast, those who had cerebral vascular lesions, the memory index and the executive function were reduced.

In a US cohort between 2001-2011 with 23951 patients, those who presented neurological complications had twice the probability to be transferred to a chronic care facility, there was an increase of 10 hospitalization days and there was a difference of $\$ 150000$ dollars respect to the group that did not present them [17]. Furthermore, the pediatric population had a higher risk of complications than adults but the group of more than 65 years presented greater mortality with an $\mathrm{OR}=2.31$ (95\%CI 1.892.84 and $\mathrm{p}<0.0001)$; the cardiopulmonary arrest was the most important risk factor in mortality and incidence of neurological complications with $\mathrm{OR}=1.49$ (95\%CI $1.38-1.60$ and $\mathrm{p}<0.0001)$ and $\mathrm{OR}=1.30(95 \% \mathrm{CI} 1.17-1.45$ and $\mathrm{p}<0.0001)$ respectively. In relation to the pediatric population intervened with ECMO, up to $50 \%$ of disability has been reported after a cognitive evaluation at the time of starting school; these patients had a diagnosis of epilepsy, cerebral palsy, delay in motor and language development [18]; and in those surviving adolescents, faults in working memory, visualspatial and verbal memory had been documented, besides this population has the tendency to depressive behavior and poor social interaction [19].

\section{Conclusion}

It can be concluded that no patient receiving ECMO therapy is exempt from suffering any neurological complication, which if presented, can overshadow at that time the vital and functional prognosis, therefore it is important to determine the risk factors of each individual to intervene those that can and avoid any neurological syndromes as far as possible; unfortunately, there are not many tools for early diagnosis of events and thus intervene them quickly. It is important to recognize that although the functional prognosis in the acute time is greatly affected, in the medium and long term each patient has a rehabilitation potential that is inherent and variable and the incidence of a neurological complication should not be the reason to consider discontinuing supportive therapy.

\section{References}

1. Risnes I, Wagner K, Nome T, Sundet K, Jensen J, et al. (2006) Cerebral outcome in adult patients treated with extracorporeal membrane oxygenation. Ann Thorac Surg 81(4): 1401-1406.

2. Nguyen DN, Huyghens L, Wellens F, Schiettecatte J, Smitz J, et al. (2014) Serum S100B Protein Could Help to Detect Cerebral Complications Associated with Extracorporeal Membrane Oxygenation (ECMO). Neurocrit Care 20(3): 367-374.

3. Xie A, Lo P, Yan TD, Forrest P (2017) Neurologic Complications of Extracorporeal Membrane Oxygenation: A Review. J Cardiothorac Vasc Anesth 31(5): 1836-1846.
4. Samadi B, Nguyen D, Rudham S, Barnett Y (2016) Spinal Cord Infarct During Concomitant Circulatory Support with Intra-Aortic Balloon Pump and Veno-Arterial Extracorporeal Membrane Oxygenation. Crit Care Med 44(2): 101-105.

5. Lorusso R, Barili F, Mauro M Di, Gelsomino S, Parise O, et al. (2016) In-Hospital Neurologic Complications in Adult Patients Undergoing Venoarterial Extracorporeal Membrane Oxygenation: Results From the Extracorporeal Life Support Organization Registry. Crit Care Med 44(10): 964-972.

6. Sutter R, Tisljar K, Marsch S (2018) Acute neurologic complications during extracorporeal membrane oxygenation: A systematic review. Crit Care Med 46(9): 1506-1513.

7. Graber LC, Quillinan N, Marrotte EJ, McDonagh DL, Bartels K (2015) Neurocognitive outcomes after extracorporeal membrane oxygenation. Best Pract Res Clin Anaesthesiol 29(2): 125-135.

8. Guennec L, Cholet C, Huang F, Schmidt M, Bréchot N, et al. (2018) Brain injury during veno-arterial extracorporeal membrane oxygenation. Ann Intensive Care 8(1): 129-139.

9. Wong JK, Smith TN, Pitcher HT, Hirose H, Cavarocchi NC (2012) Cerebral and lower limb near-infrared spectroscopy in adults on extracorporeal membrane oxygenation. Artif Organs 36(8): 659-667.

10. Zanatta P, Forti A, Bosco E, Salvador L, Borsato M, et al. (2010) Microembolic signals and strategy to prevent gas embolism during extracorporeal membrane oxygenation. J Cardiothorac Surg 5: 5.

11. Dejode JM, Antonini F, Lagier P, Martin C (2001) Capgras syndrome: A clinical manifestation of watershed cerebral infarct complicating the use of extracorporeal membrane oxygenation. Crit Care 5(4): 232-235.

12. Bembea MM, Savage W, Strouse JJ, Schwartz JM, Graham E, et al. (2011) Glial fibrillary acidic protein as a brain injury biomarker in children undergoing extracorporeal membrane oxygenation. Pediatr Crit Care Med 12(5): 572-579.

13. Floerchinger B, Philipp A, Foltan M, Keyser A, Camboni D, et al. (2014) Neuron-specific enolase serum levels predict severe neuronal injury after extracorporeal life support in resuscitation. Eur J cardio-thoracic Surg Off J Eur Assoc Cardio-thoracic Surg 45(3): 496-501.

14. Luyt CE, Bréchot N, Demondion P, Jovanovic T, Hékimian G, et al. (2016) Brain injury during venovenous extracorporeal membrane oxygenation. Intensive Care Med 42(5): 897-907.

15. Martucci G, Lo Re V, Arcadipane A (2016) Neurological injuries and extracorporeal membrane oxygenation: the challenge of the new ECMO era. Neurol Sci 37(7): 1133-1136.

16. Von Bahr V, Kalzén H, Hultman J, Frenckner B, Andersson C, et al. (2018) Long-term cognitive outcome and brain imaging in adults after extracorporeal membrane oxygenation. Crit Care Med 46(5): 351-358.

17. Nasr D, Rabinstein A (2015) Neurologic Complications of Extracorporeal Membrane Oxygenation: A Review. J Clin Neurol 11(4): 383-389.

18. Waitzer E, Riley SP, Perreault T, Shevell MI (2009) Neurologic outcome at school entry for newborns treated with extracorporeal membrane oxygenation for noncardiac indications. J Child Neurol 24(7): 801-806.

19. Madderom MJ, Schiller RM, Gischler SJ, van Heijst AFJ, Tibboel D, et al. (2016) Growing Up After Critical Illness: Verbal, Visual-Spatial, and Working Memory Problems in Neonatal Extracorporeal Membrane Oxygenation Survivors. Crit Care Med 44(6): 1182-1190. 
ISSN: 2574-1241

DOI: 10.26717/BJSTR.2019.18.003225

Cristian Eduardo Navarro. Biomed J Sci \& Tech Res

(c) This work is licensed under Creative

Submission Link: https://biomedres.us/submit-manuscript.php

$\begin{array}{ll}\begin{array}{l}\text { BIOMEDICAL } \\ \text { RESEARCHES }\end{array} & \text { Assets of Publishing with us } \\ \text { - Global archiving of articles } \\ \text { - Immediate, unrestricted online access } \\ \text { - Rigorous Peer Review Process } \\ \text { https://biomedres.us/ }\end{array}$

